\title{
Minireview \\ Fatigue and cancer: causes, prevalence and treatment approaches
}

\author{
LI Wagner*,I and D Cella' \\ 'Center on Outcomes, Research and Education, Evanston Northwestern Healthcare, Robert H Lurie Comprehensive Cancer Center of Northwestem \\ University, Northwestern University Feinberg Medical School, Chicago, IL, USA
}

Fatigue is the most prevalent cancer-related symptom and has a significant adverse impact on patients' functional ability and quality of life. Hypotheses regarding the aetiology of cancer-related fatigue are discussed, and clinical practice guidelines for the evaluation and management of oncology patients with fatigue are reviewed. Both nonpharmacologic and pharmacologic strategies for the management of fatigue are summarised.

British Journal of Cancer (2004) 91, 822-828. doi:I0.1038/sj.bjc.66020I2 www.bjcancer.com

Published online 6 July 2004

(c) 2004 Cancer Research UK

Keywords: cancer-related fatigue; cancer symptom management

Publications on cancer-related fatigue were identified through Medline searches based on keywords (search terms cancer and fatigue, cancer-related fatigue, cancer and fatigue and intervention, cancer and fatigue and treatment) and based on authors who have published many articles on cancer-related fatigue or cancer-related symptom management, limited to 1966-2004. A narrative review of reference sections from recently published journal articles, review articles, and textbook chapters was also conducted. The brief nature of this review article does not allow for a comprehensive presentation of results from these searches. A hierarchical approach was used to select publications for inclusion in this review. When possible, priority was given to publications that were based on the most methodologically sound research studies. As cancer-related fatigue is still a relatively new area for research, exploratory or pilot results are cited when results from larger studies are not available.

Owing to increasingly earlier detection and improving therapies, the life expectancy of people with cancer has been increasing. As a result, cancer has become a chronic illness for most patients. Understanding the aetiology of cancer-related symptoms and the identification of efficacious clinical management strategies are therefore needed. Fatigue is the most prevalent cancer-related symptom and is associated with significant morbidity, functional impairments and reduced quality of life. Therefore, the effective management of fatigue would significantly reduce disease burden associated with cancer and its treatments.

Research in the area of cancer-related fatigue lags behind attention that has been given to cancer pain, nausea and vomiting (Curt and Johnston, 2003; Morrow et al, 2002). Recognising this issue, the US National Institutes of Health (NIH) recently held a State-of-the-Science Conference on Symptom Management in Cancer to discuss the clinical management of pain, depression

\footnotetext{
*Correspondence: Dr LI Wagner, Northwestern University, 339 E Chicago Avenue, Wieboldt Hall 717, Chicago, IL 606II, USA;

E-mail: Iwagner@northwestern.edu

Received 13 February 2004; revised 10 May 2004; accepted 26 May 2004; published online 6 July 2004
}

and fatigue as priorities for advancing clinical care (National Institutes of Health, 2002).

\section{PREVALENCE OF CANCER-RELATED FATIGUE}

Fatigue has been described as a nearly universal symptom among cancer patients by the National Comprehensive Cancer Network (NCCN) Cancer-Related Fatigue Panel (Mock et al, 2000). Depending on the patient sample and methodology employed, it is estimated that approximately $60-96 \%$ of cancer patients who are undergoing cancer treatments experience fatigue (Cella, 1998). Fatigue is extremely common among cancer patients undergoing cytotoxic chemotherapy, radiation therapy, bone marrow transplant or treatment with biological response modifiers (Irvine et al, 1994; Dean et al, 1995; Hann et al, 1999; Jacobsen et al, 1999). For a significant number of patients, fatigue persists after treatment is completed. Broeckel et al (1998) examined a sample of disease-free breast cancer patients who were a mean of 16 months postchemotherapy, and found patients' average fatigue to be $50 \%$ higher than that reported by a comparison group of women who did not have cancer. Bower et al (2003) assessed breast cancer survivors who were an average of 2.8-3 years postdiagnosis and found that survivors' average level of fatigue was comparable to that of age-matched women in the general population. Breast cancer survivors' fatigue scores were higher than a demographically and socioeconomically similar healthy group of women at risk for breast cancer.

\section{AETIOLOGY OF CANCER-RELATED FATIGUE}

The pathophysiology of fatigue is poorly understood and few basic research studies have been conducted to investigate the physiological mechanisms underlying cancer-related fatigue (Gutstein, 2001). Identifying the aetiological factors that contribute to fatigue often proves to be complicated, as multiple causes typically coexist and may have additive effects. Figure 1 depicts the most commonly identified causes for cancer-related fatigue. Often cited factors 


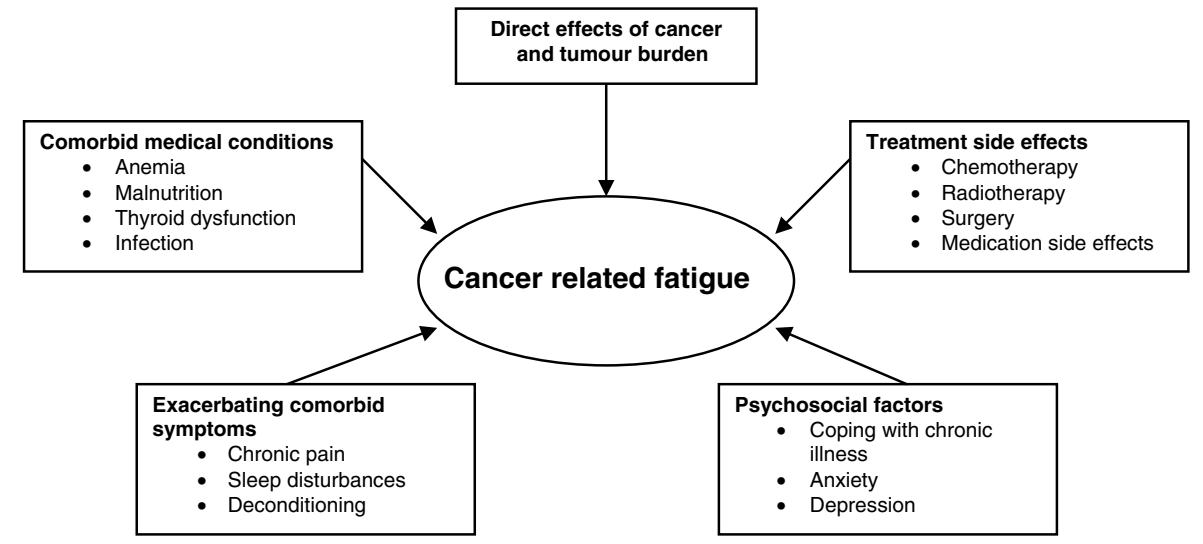

Figure I Causes of fatigue (Atkinson et al, 2002; Cella et al, 1998; Portenoy and Itri, 1999).

include the direct effects of cancer, treatment side effects, comorbid medical conditions, exacerbating comorbid symptoms and psychosocial factors.

Morrow et al (2002) reviewed the evidence supporting four hypotheses for cancer-related fatigue: (1) anemia, (2) abnormalities in adenosine triphosphate, (3) vagal afferent activation and (4) the interaction of cytokines and serotonin. The authors reviewed research pertaining to each hypothesis and concluded by highlighting findings from various independent studies that have implicated cytokines, 5-HT, and the hypothalamic-pituitary axis in the development of cancer-related fatigue. Kurzrock (2001) has discussed the role of cytokine dysregulation in cancer-related fatigue and other conditions that are commonly associated with fatigue, such as anemia, cachexia, fever, infection and depression. Specifically, Kurzrock (2001) discussed erythropoietin, interleukin, tumour necrosis factor and interferon. Bower et al (2003) compared 20 breast cancer survivors with enduring fatigue to 19 nonfatigued breast cancer survivors and their findings suggest that persistent fatigue may be associated with a T-cell mediated inflammatory process. Several models have been proposed for the pathophysiology of fatigue and promising findings have been reported in support of these models. Research in this area is preliminary and it is clear that larger, well-designed studies are required to definitively pinpoint the causes of fatigue and the associated clinical implications.

\section{DIAGNOSTIC CRITERIA FOR CANCER-RELATED FATIGUE}

The Fatigue Coalition, a multidisciplinary group of medical practitioners, researchers and patient advocates developed diagnostic criteria for cancer-related fatigue, with the goal of facilitating research and treatment planning through the availability of diagnostic criteria (Cella et al, 1998). The International Classification of Diseases-10 (ICD-10) criteria for cancer-related fatigue require 'significant fatigue, diminished energy, or increased need to rest, disproportionate to any recent change in activity level' to be present every day or nearly every day during the same 2-week period in the past month, as well as the presence of additional symptoms. A few examples of the additional symptoms that count toward a diagnosis of cancer-related fatigue include generalised weakness, diminished concentration, insomnia or hypersomnia and unrestorative sleep (for full criteria, see Cella et al, 1998). Since these are proposed criteria, there may be experts on cancer-related fatigue who would disagree with some of the additional symptoms as counting toward a diagnosis. Symptoms must cause clinically significant distress or impairment, be associated with cancer or cancer therapy, and cannot be primarily due to a comorbid psychiatric disorder. A few examples of exclusionary psychiatric conditions are provided in the criteria. One of the challenges in using these criteria to assess patients is that when a psychiatric diagnosis is present, the extent to which fatigue can be attributed to the psychiatric disorder is at the discretion of the clinician and can be difficult to determine given the overlap in symptomatology.

To evaluate these criteria, Cella et al (2001) interviewed 379 patients who received chemotherapy or chemotherapy plus radiation therapy and administered diagnostic criteria. A total of $37 \%$ of respondents reported at least 2 weeks of fatigue in the previous month and $17 \%$ of respondents met criteria for cancerrelated fatigue. Sadler et al (2002) administered diagnostic criteria to 51 patients undergoing blood or bone marrow transplantation and found that $21 \%$ met criteria for cancer-related fatigue. Comparisons among independent raters demonstrated high rates of reliability. Patients meeting criteria reported higher levels of fatigue severity, frequency, pervasiveness, and interference with quality of life and poorer role functioning, less vitality and more depressive symptoms. These results support the reliability and validity of the proposed criteria for cancer-related fatigue.

These estimates are much lower than previously reported rates for the prevalence of fatigue. Many published reports on the prevalence of cancer-related fatigue include individuals who report having fatigue in prevalence estimates, regardless of the severity of fatigue. The use of diagnostic criteria represents a more stringent approach to estimating the prevalence of cancer-related fatigue, thus prevalence estimates based on these criteria are lower and the cases that are identified include participants with greater severity of fatigue and associated functional impairments. Given the overlap with major depressive disorder, diagnostic criteria for cancer-related fatigue may be useful in identifying patients with fatigue who may respond to antidepressant therapy (Jacobsen et al, 2003).

\section{CLINICAL SIGNIFICANCE OF CANCER-RELATED FATIGUE}

Cancer-related fatigue significantly impairs patients' quality of life and ability to function. Based on a sample of 397 patients, $91 \%$ of respondents with fatigue reported that fatigue prevented them from leading a 'normal' life, $88 \%$ reported an alteration in their daily routine due to fatigue, and of patients who were employed $75 \%$ changed their employment status because of their fatigue (Curt et al, 2000). Vogelzang et al (1997) interviewed 419 cancer patients and patients reported that fatigue adversely affected their daily lives more than pain $(61 \%$ vs $19 \%)$. However, in a comparable survey of oncologists, respondents believed that pain 
adversely affected their patients more than fatigue $(61,37 \%$, respectively). In addition to interfering with patients' quality of life and functional status, cancer-related fatigue may also disrupt treatments for cancer. Vogelzang et al (1997) found that approximately one-third of patients interviewed reported that fatigue impacted patients' concerns regarding their mortality or compromised their hope of fighting the illness. The relationship between symptom management and cancer treatment adherence has been identified as a priority for investigation by the US National Institutes of Health (2002).

\section{CLINICAL MANAGEMENT OF CANCER-RELATED FATIGUE}

For clinical interventions to be effective, patients with fatigue who would benefit from treatment must first be identified. The extent to which fatigue is underassessed and undertreated has been documented. Vogelzang et al (1997) interviewed 419 cancer patients and found that among fatigued patients, $50 \%$ did not discuss treatment options for fatigue with their oncologists and only $27 \%$ reported that their oncologist offered treatment recommendations for their fatigue. Curt et al (2000) similarly reported that $40 \%$ of patients with fatigue did not receive any treatment recommendations. Clinical practice guidelines for the management of fatigue have been established (Portenoy and Itri, 1999; Mock et al, 2000). Interdisciplinary evaluation and treatment is recommended to adequately assess and manage the complex interaction of medical, psychological and social factors that impact fatigue characteristics and associated decrements in quality of life.

\section{Screening for fatigue}

Depending on available resources, busy clinical settings may benefit from implementing screening tools to identify patients with more severe fatigue so that these patients can be targeted for indepth assessment and treatment. The effectiveness of single item or brief measures to identify cancer patients who may benefit from assessment and treatment for fatigue has been demonstrated (Kirsh et al, 2001). National Comprehensive Cancer Network recommends the use of a single item to assess fatigue severity on a $0-10$ scale. To identify the cutoff score on a $0-10$ scale that maximises sensitivity and specificity in detecting cases of more severe fatigue, Wagner et al (2003a) administered a single-item screening for fatigue and a longer measure of fatigue (Functional Assessment of Cancer Therapy - Fatigue subscale, FACT-F) to 105 outpatients who were receiving chemotherapy. A cutoff of 5 was the optimal level for detecting 'cases' of clinically significant fatigue as defined by exceeding an established threshold for caseness on the FACT-F. The suggested cutoff of 5 can be used as a guide for clinical practice. Additional factors should be considered when determining the optimal cutoff score for a particular clinical setting. Resources that are available to further assess and treat patients with fatigue should be taken into account when deciding on a cutoff score to target patients for more in-depth assessment and treatment when indicated. Clinics with staff available to conduct follow-up assessment on identified patients could afford to set a low cutoff score to identify all patients who have fatigue regardless of severity, whereas clinical settings with limited resources may need to set a higher cutoff score to identify only those patients with moderately severe to severe fatigue for focused intervention.

\section{Assessing patients with clinically significant fatigue}

Given the diverse aetiological factors that contribute to fatigue and its multidimensional nature, the comprehensive assessment of patients with fatigue is required for the development of effective treatment interventions. Clinical practice guidelines for fatigue assessment and management emphasise the need to evaluate (1) fatigue characteristics and (2) disease status and treatment. Guidelines also recommend obtaining a history and physical checkup and conducting laboratory studies as indicated to rule out common, treatable causes of fatigue, such as anemia or thyroid dysfunction (Portenoy and Itri, 1999; Mock et al, 2000). An indepth fatigue assessment should include fatigue severity, temporal characteristics (e.g. onset, duration), exacerbating and alleviating factors, impact on functioning and quality of life, symptom-related distress, and other symptoms that commonly co-occur with fatigue such as pain, menopausal symptoms, sleep disturbances, depression and cognitive dysfunction. Since fatigue is a subjective sensation, it is important to use validated, standardised assessment instruments. Many standardised instruments have been developed for the assessment of fatigue and its impact on quality of life (for a review, see Wagner and Cella, 2001).

\section{Interventions for cancer-related fatigue}

The brief nature of this article does not allow a comprehensive review of empirical support for interventions to treat cancerrelated fatigue. Priority was given to randomised clinical trials (RCTs) with fatigue as a primary end point. For interventions with several published RCTs (e.g. psychosocial interventions), results from less methodologically rigorous studies were not presented. For interventions that have not been as extensively investigated, open-label studies and pilot studies are cited. Clinical practice guidelines developed by the NCCN Cancer-Related Fatigue Panel (Mock et al, 2000) through evidence-based and consensus review are used to guide the discussion.

National Comprehensive Cancer Network Cancer-Related Fatigue Guidelines recommend a two-stage approach to the treatment of cancer-related fatigue. The first step in treating fatigued cancer patients is to identify and address any treatable contributing factors that may be causing the fatigue. National Comprehensive Cancer Network guidelines identify several commonly observed treatable contributing factors, including pain, emotional distress, anemia, sleep disturbance, nutritional inadequacies, deconditioning due to decreased activity and comorbidities (e.g. infection, cardiac dysfunction, renal dysfunction). Significant improvements in quality of life have been demonstrated among anemic cancer patients after treatment with erythropoietic agents (Demetri et al, 1998; Cella et al, in press).

Based on NCCN guidelines, the second step involves the management of any residual fatigue that continues after treatable contributing factors have been resolved or fatigue that continues despite the lack of any identified treatable contributing factors. To place treatment strategies in the context of the patient's clinical status, separate algorithms are provided for patients receiving active cancer treatment, patients receiving disease-free long-term follow-up, and patients receiving care at the end of life. Fatigue management includes providing education and counselling to patients and their families, self-management strategies that patients can utilise, nonpharmacologic interventions and pharmacologic treatments. Education and counselling should emphasise that fatigue is commonly experienced by patients undergoing treatment for cancer and is not necessarily an indicator of disease progression (if appropriate). National Comprehensive Cancer Network guidelines identify several strategies that patients may find useful for managing their fatigue, including energy conservation techniques such as prioritising activities, pacing (alternating physically demanding with more sedentary activities), scheduling activities at times of peak energy, taking naps as long as they do not interfere with night-time sleep and following a structured daily routine. Distraction through engaging in pleasurable activities is also recommended. Barsevick et al (2004) randomised cancer patients who were initiating chemotherapy or radiotherapy to an 
energy conservation and activity management (ECAM) intervention $(n=200)$ or to a control intervention that was similar in terms of time and attention $(n=196)$. Both interventions included three telephone sessions with an oncology nurse during the first 3-5 weeks of treatment. A statistically significant difference in fatigue over time was reported, with ECAM participants reporting a greater decrease in fatigue over time compared to control participants. No differences in functional performance were observed.

National Comprehensive Cancer Network guidelines recommend the following nonpharmacologic interventions: exercise, restorative therapy, nutrition consultation, sleep hygiene and psychosocial interventions. Of these interventions, the effectiveness of exercise in reducing fatigue and increasing functional abilities has received the most empirical support. Table 1 summarises results from six studies that examined exercise to treat cancer-related fatigue, four of which were randomised, controlled trials. Reductions in fatigue were reported from all six trials. Types of exercise included a home-based walking programme, a bed cycle ergometer, resistance exercise or patientselected exercise. It is important to highlight the strength of the empirical support for exercise in treating cancer-related fatigue, since the most common treatment recommendation given to patients by their health care providers was bed rest and relaxation (Curt et al, 2000). According to NCCN guidelines, contraindications to exercise include bone metastases, neutropenia, thrombocytopenia and fever.

Psychosocial interventions have also received empirical support for the treatment of cancer-related fatigue, as demonstrated in
Table 2. Seven randomised clinical trials to evaluate supportive interventions (group and individual), education and stress management groups, coping strategies training and behavioural interventions to assist patients with managing their fatigue have been published with impressive results. Given et al (2004) conducted a randomised clinical trial to evaluate a cognitive behavioural intervention to reduce cancer-related symptom burden. The investigators found that a 20-week (10 contacts) cognitive behavioural intervention demonstrated significant impact on severity of cancer-related symptoms after four contacts (10 weeks), and this reduction was maintained at 20 weeks among those patients who entered the trial with moderate to severe symptoms.

Pharmacological interventions may also be useful for the management of cancer-related fatigue, although research in this area is limited since the few studies that have been published have methodological shortcomings (Portenoy and Itri, 1999). Classes of potentially useful medications include erythropoietic agents (when anemia is present), psychostimulants, selective serotonin-reuptake inhibitors and low-dose corticosteroids. Dosing guidelines for erythropoietic agents to treat anemia have been established (see NCCN Cancer and Treatment-Related Anemia guidelines as an example, www.nccn.org).

Table 3 summarises research on the efficacy of psychostimulants in treating fatigue among cancer patients, the elderly and patients with multiple sclerosis. Examples of psychostimulants include methylphenidate, modafinil, pemoline and dextroamphetamine. Controlled, randomised trials have yielded evidence to support the

Table I Nonpharmacological interventions: exercise

\begin{tabular}{|c|c|c|c|c|c|}
\hline Author & Sample characteristics & Sample size & Design & Type of exercise & Results \\
\hline Dimeo et al (1999) & $\begin{array}{l}\text { Mixed (Hem and solid } \\
\text { tumour) }\end{array}$ & 59 & $\mathrm{RCT}$ & Bed cycle ergometer (biking) & $\downarrow$ Fatigue \\
\hline Mock et al (200I) & Breast cancer Stage I- III & 52 & $\mathrm{RCT}$ & $\begin{array}{l}\text { Home-based walking programme } 4- \\
5 \times \text { week }^{-1} \text { for } 30 \mathrm{~min}\end{array}$ & $\downarrow$ Fatigue, $\uparrow$ walking ability \\
\hline Mock et al (2002) & Breast cancer Stage I-III & $|1|$ & $\mathrm{RCT}$ & $\begin{array}{l}\text { Home-based walking programme } 4- \\
5 \times \text { week }^{-1} \text { for } 30 \mathrm{~min}\end{array}$ & $\downarrow$ Fatigue, $\uparrow$ walking \\
\hline Schwartz et al (200I) & Breast cancer Stage II & 61 & Within subjects & $\begin{array}{l}\text { Home-based walking programme or } \\
\text { patient choice } 3-4 \times \text { week }^{-1} \text { for } \\
15-30 \text { min }\end{array}$ & $\downarrow$ Fatigue, $\uparrow$ walking ability \\
\hline Schwartz et al (2002) & $\begin{array}{l}\text { Melanoma patients treated } \\
\text { with interferon-a }\end{array}$ & $\begin{array}{l}12+16 \text { historical } \\
\text { controls }\end{array}$ & Quasi-experimental & $\begin{array}{l}\text { Patient-selected } 4 \times \text { week }^{-1} \text { for } \\
15 \text { min }+ \text { methylphenidate } 20 \mathrm{mg} \text { QD }\end{array}$ & $\begin{array}{l}\downarrow \text { Fatigue, } \uparrow \text { functional } \\
\text { ability }\end{array}$ \\
\hline Segal et al (2003) & $\begin{array}{l}\text { Prostate cancer receiving } \\
\text { androgen ablation }\end{array}$ & 155 & $\mathrm{RCT}$ & Resistance exercise & $\begin{array}{l}\downarrow \text { Fatigue, } \uparrow \text { quality of life, } \\
\uparrow \text { muscular fitness }\end{array}$ \\
\hline
\end{tabular}

$\mathrm{RCT}=$ randomised clinical trial.

Table 2 Nonpharmalogical interventions: psychosocial

\begin{tabular}{|c|c|c|c|c|c|}
\hline Author & Sample characteristics & $\begin{array}{l}\text { Sample } \\
\text { size }\end{array}$ & Design & Type of intervention & Results \\
\hline Spiegel et al (1981) & Breast cancer Stage IV & 86 & $\mathrm{RCT}$ & Support group weekly I year & $\begin{array}{l}\downarrow \text { Fatigue, anxiety, mood } \\
\text { disturbance }\end{array}$ \\
\hline Forester et al (1985) & $\begin{array}{l}\text { Mixed cancer in radiation } \\
\text { therapy }\end{array}$ & 100 & $\mathrm{RCT}$ & Individual psychotherapy 10 weeks & $\begin{array}{l}\downarrow \text { Fatigue, emotional } \\
\text { symptoms, physical symptoms }\end{array}$ \\
\hline Fawzy et al (1990) & $\begin{array}{l}\text { Melanoma postsurgery Stage } \\
\mid-\|\end{array}$ & 66 & RCT & $\begin{array}{l}\text { Support group including education and stress } \\
\text { management } 6 \text { weeks }\end{array}$ & $\begin{array}{l}\downarrow \text { Fatigue, depression, mood } \\
\text { disturbance }\end{array}$ \\
\hline Fawzy (1995) & Melanoma Stage I-II & 61 & RCT & Individual education and RN support $3 \mathrm{~h}$ & $\begin{array}{l}\downarrow \text { Fatigue, anxiety, mood } \\
\text { disturbance }\end{array}$ \\
\hline $\begin{array}{l}\text { Gaston-Johansson et al } \\
\text { (2000) }\end{array}$ & $\begin{array}{l}\text { Autologous bone marrow } \\
\text { transplantation }\end{array}$ & 110 & $\mathrm{RCT}$ & Coping strategy programme & $\downarrow$ Fatigue and nausea \\
\hline Given et al (2004) & $\begin{array}{l}\text { Mixed solid tumour and } \\
\text { lymphoma }\end{array}$ & 237 & $\mathrm{RCT}$ & Tailored behavioural intervention 8 weeks & $\downarrow$ Fatigue and pain \\
\hline Jacobsen et al (2002) & Mixed cancer in chemotherapy & 411 & $\mathrm{RCT}$ & $\begin{array}{l}\text { Professionally or self-administered stress } \\
\text { management training }\end{array}$ & $\uparrow$ Vitality and mental health \\
\hline
\end{tabular}

$\mathrm{RCT}=$ randomised clinical trial. 
Table 3 Pharmalogic interventions: psychostimulants

\begin{tabular}{|c|c|c|c|c|c|}
\hline Author & Sample characteristics & $\begin{array}{l}\text { Sample } \\
\text { size }\end{array}$ & Design & Medication & Results \\
\hline Bruera et al (1987) & $\begin{array}{l}\text { Advanced cancer with chronic } \\
\text { pain }\end{array}$ & 32 & $\begin{array}{l}\text { Open- } \\
\text { label }\end{array}$ & Methylphenidate & $\downarrow$ Psychomotor slowing, $\uparrow$ physical activity \\
\hline Bruera et al (2003) & Advanced cancer & 31 & $\begin{array}{l}\text { Open- } \\
\text { label }\end{array}$ & Methylphenidate & $\downarrow$ Fatigue, $\uparrow$ quality of life, $\uparrow$ sleep quality \\
\hline Wilwerding et al (1995) & $\begin{array}{l}\text { Cancer patients receiving } \\
\text { opioids }\end{array}$ & 43 & $\mathrm{RCT}$ & Methylphenidate & $\downarrow$ Somnolence \\
\hline Meyers et al (1998) & Primary brain tumour & 30 & $\begin{array}{l}\text { Within } \\
\text { subjects }\end{array}$ & Methylphenidate & $\begin{array}{l}\downarrow \text { Psychomotor slowing, } \uparrow \text { cognitive } \\
\text { functioning }\end{array}$ \\
\hline Rammohan et al (2002) & Multiple sclerosis & 72 & RCT & Modafinil & $\downarrow$ Fatigue \\
\hline Krupp et al (1995) & Multiple sclerosis & 93 & $\mathrm{RCT}$ & $\begin{array}{l}\text { Amantadine, pemoline, or } \\
\text { placebo }\end{array}$ & $\begin{array}{l}\text { Amantadine:, } \downarrow \text { fatigue, pemoline: fatigue } \\
\text { severity same as placebo }\end{array}$ \\
\hline Weinshenker et al (1992) & Multiple sclerosis & 46 & $\mathrm{RCT}$ & Pemoline & $\downarrow$ Fatigue $(P=0.06)$ \\
\hline
\end{tabular}

$\mathrm{RCT}=$ randomised clinical trial.

Table 4 Interventions: current status of empirical support for clinical management strategies for cancer-related fatigue

\begin{tabular}{lccc}
\hline & $\begin{array}{c}\text { Empirical } \\
\text { support }\end{array}$ & $\begin{array}{c}\text { Demonstrated } \\
\text { in other } \\
\text { diseases }\end{array}$ & $\begin{array}{c}\text { Additional } \\
\text { research } \\
\text { needed }\end{array}$ \\
\hline $\begin{array}{l}\text { Exercise } \\
\text { Psychosocial interventions }\end{array}$ & $\times$ & & \\
$\begin{array}{l}\text { Erythropoetic agents (if } \\
\text { anemia is present) }\end{array}$ & $\times$ & & \\
$\begin{array}{l}\text { Psychostimulants } \\
\text { Selective serotonin } \\
\text { reuptake inhibitors (SSRIs) }\end{array}$ & & & $\times$ \\
Low-dose corticosteroids & & $\times$ & $\times$ \\
\hline
\end{tabular}

relative efficacy of psychostimulants in treating fatigue associated with opioid administration among cancer patients (Wilwerding et al, 1995). Bruera et al (2003) conducted a prospective open-label trial with advanced cancer outpatients who had fatigue $>4(0-10$ scale) to evaluate the effects of patient-controlled methylphenidate for cancer-related fatigue. FACIT-F (Functional Assessment of Chronic Illness Therapy - Fatigue) scores and Edmonton Symptom Assessment Scale (ESAS) scores showed significant improvement in fatigue after 7 days of treatment, with no reported serious side effects. Schwartz et al (2002) found that methylphenidate combined with exercise reduced fatigue among interferontreated melanoma patients (see Table 1). The efficacy of modafinil in treating fatigue secondary to multiple sclerosis was demonstrated in a Phase II trial (Rammohan et al, 2002). A trial of modafinil to treat cancer-related fatigue is currently underway. Weinshenker et al (1992) evaluated pemoline for the treatment of fatigue among patients with multiple sclerosis and found a trend suggesting reduced fatigue among patients who received pemoline compared to placebo $(P<0.06)$. Krupp et al $(1995)$ conducted a randomised, clinical trial to compare amantadine, pemoline, or placebo for the treatment of fatigue in patients with multiple sclerosis. Patients who received amantadine had significantly less fatigue compared to those receiving pemoline or placebo. However, patients receiving pemoline did not differ from patients who received placebo in reported fatigue severity.

\section{REFERENCES}

Atkinson A, Barsevick A, Cella D, Cimprich B, Cleeland C, Donnelly J, Eisenberg MA, Escalante C, Hinds P, Jacobsen PB, Kaldor P, Knight SJ, Peterman A, Piper BF, Rugo H, Sabbatini P, Stahl C, the National Comprehensive Cancer Network (2000) NCCN Practice Guidelines for Cancer-Related Fatigue. Oncology 14: 151-161
National Comprehensive Cancer Network guidelines recommend antidepressants for fatigue management, particularly when depression is present. While the close association between fatigue and depression suggests that antidepressants may have a role in treating cancer-related fatigue, research in this area has not been supportive of this class of medications. Morrow et al (2003) conducted a randomised, double-blind trial comparing 244 patients who received paroxetine to 235 patients treated with placebo. Patients treated with paroxetine reported less depressive symptoms at follow-up; however, no differences in fatigue severity were observed.

Clinical observation and limited data from controlled trials suggests that low-dose cortisteroids may have a role in treating cancer-related fatigue, specifically dexamethasone and prednisone. Bruera et al (1990) demonstrated the efficacy of megestrol acetate to manage cachexia and multiple symptoms including fatigue among advanced cancer patients.

In sum, pharmacological approaches to the management of cancer-related hold promise, particularly psychostimulants. It is clear that randomised clinical trials with all of these agents are needed to advance the development of efficacious treatment approaches. Table 4 summarises the current status of empirical support for nonpharmacological and pharmacological fatigue management strategies.

\section{CONCLUSION}

Fatigue is a symptom commonly associated with cancer and its treatments. The mechanisms underlying the development and maintenance of fatigue are poorly understood. Fatigue is multifactorial in its aetiology and manifestation. Empirical support for exercise and psychosocial interventions for fatigue have been reported. Pharmacological treatments currently in use are based on limited research studies. Short-term goals of clinical research on cancer-related fatigue should focus on an improved understanding of the aetiology of fatigue, relationships between fatigue and co-occurring symptoms, and evaluating treatment interventions (National Institutes of Health, 2002; Wagner et al, 2003b). Well-designed clinical trials are urgently needed for the development of empirically supported fatigue management strategies to reduce the symptom burden associated with cancer.
Barsevick AM, Dudley W, Beck S, Sweeney C, Whitmer K, Nail L (2004) A randomized clinical trial of energy conservation for patients with cancerrelated fatigue. Cancer 100: 1302-1310

Bower JE, Ganz PA, Aziz N, Fahey JL, Cole SW (2003) T-Cell homeostasis in breast cancer survivors with persistent fatigue. J Natl Cancer Inst 15: 1165- 1168 
Broeckel JA, Jacobsen PB, Horton J, Balducci L, Lyman GH (1998) Characteristics and correlates of fatigue after adjuvant chemotherapy for breast cancer. J Clin Oncol 16: 1689-1696

Bruera E, Chadwick S, Brenneis C, Hanson J, MacDonald RN (1987) Methylphenidate associated with narcotics for the treatment of cancer pain. Cancer Treat Rep 71: 67-70

Bruera E, Driver L, Barnes EA, Willey J, Shen L, Palmer JL, Escalante C (2003) Patient-controlled methylphenidate for the management of fatigue in patients with advanced cancer: A preliminary report. J Clin Oncol 21: $4439-4443$

Bruera E, Macmillan K, Kuehn N, Hanson J, MacDonald RN (1990) A controlled trial of megestrol acetate on appetite, caloric intake, nutritional status, and other symptoms in patients with advanced cancer. Cancer 66: $1279-1282$

Cella D (1998) Quality of life in cancer patients experiencing fatigue and anemia. Anemia Oncol 2-4

Cella D, Davis K, Breitbart W, Curt G, for the Fatigue Coalition (2001) Cancer-related fatigue: prevalence of proposed diagnostic criteria in a United States sample of cancer survivors. J Clin Oncol 19: $3385-3391$

Cella D, Kallich J, McDermott A, Xu X (2004) The longitudinal relationship of hemoglobin, fatigue and quality of life in anemic cancer patients: Results from five randomized clinical trials. Ann Oncol 15: 979-986

Cella D, Peterman A, Passik S, Jacobsen P, Breitbart W (1998) Progress toward guidelines for the management of fatigue. Oncology 12: 369-377

Curt GA, Breitbart W, Cella D, Groopman JE, Horning SJ, Itri LM, Johnson DH, Miaskowski C, Scherr SL, Portenoy RK, Vogelzang NJ (2000) Impact of cancer-related fatigue on the lives of patients: new findings from the fatigue coalition. Oncologist 5: 353-360

Curt G, Johnston PG (2003) Cancer fatigue: the way forward. Oncologist 8(Suppl 1): $27-30$

Dean GE, Spears L, Ferrell BR, Quan WD, Groshon S, Mitchell MS (1995) Fatigue in patients with cancer receiving interferon alpha. Cancer Pract 3: $164-172$

Demetri GD, Kris M, Wade J, Degos L, Cella D (1998) Quality of life benefit in chemotherapy patients treated with epoetin alfa is independent of disease response tumor or tumor type: results from a prospective community oncology study. J Clin Oncol 16: 3412 -3425

Dimeo FC, Stieglitz RD, Novelli-Fischer U, Fetscher S, Keul J (1999) Effects of physical activity on the fatigue and psychologic status of cancer patients during chemotherapy. Cancer 85: 2273-2277

Fawzy FI, Cousins N, Fawzy NW, Kemeny ME, Elashoff R, Morton D (1990) A structured psychiatric intervention for cancer patients. I. Changes over time in methods of coping and affective disturbance. Arch Gen Psychiatry 47: $720-725$

Fawzy NW (1995) A psychoeducational nursing intervention to enhance coping and affective state in newly diagnosed malignant melanoma patients. Cancer Nurs 18: $427-438$

Forester B, Kornfeld DS, Fleiss JL (1985) Psychotherapy during radiotherapy: effects on emotional and physical distress. Am J Psychiatry 142: $22-27$

Gaston-Johansson F, Fall-Dickson JM, Nanda J, Ohly KV, Stillman S, Krumm S, Kennedy MJ (2000) The effectiveness of the comprehensive coping strategy program on clinical outcomes in breast cancer autologous bone marrow transplantation. Cancer Nurs 23: $277-285$

Given C, Given B, Rahbar M, Jeon S, McCorkle R, Cimprich B, Galaecki A, Kozachik S, Brady A, Fisher-Malloy MJ, Courtney K, Bowie E (2004) Effect of a cognitive behavioral intervention on reducing symptom severity during chemotherapy. J Clin Oncol 22: 507-516

Gutstein HB (2001) The biologic basis of fatigue. Cancer 92: 1678-1683

Hann DM, Garovoy N, Finkelstein B (1999) Fatigue and quality of life in breast cancer patients undergoing autologous stem cell transplantation: a longitudinal comparative study. J Pain Symptom Manage 17: $311-319$

Irvine D, Vincent L, Graydon JE, Bubela N, Thompson L (1994) The prevalence and correlates of fatigue in patients receiving treatment with chemotherapy and radiotherapy: a comparison with the fatigue experienced by healthy individuals. Cancer Nurs 17: 367-378

Jacobsen PB, Donovan KA, Weitzner MA (2003) Distinguishing fatigue and depression in patients with cancer. Semin Clin Neuropsychiatry 8: 229240

Jacobsen PB, Hann DM, Azzarello LM, Horton J, Balducci L, Lyman GH (1999) Fatigue in women receiving adjuvant chemotherapy for breast cancer: characteristics, course, and correlates. J Pain Symptom Manage 18: $233-242$

Jacobsen PB, Meade CD, Stein KD, Chirikos TN, Small BJ, Ruckdeschel JC (2002) Efficacy and costs of two forms of stress management training for cancer patients undergoing chemotherapy. J Clin Oncol 20: $2851-2862$

Kirsh KL, Passik S, Holtsclaw E, Donaghy K, Theobald D (2001) I get tired for no reason: a single item screening for cancer-related fatigue. J Pain Symptom Manage 22: 931 - 937

Krupp LB, Coyle PK, Doscher C, Miller A, Cross AH, Jandorf L, Halper J, Johnson B, Morgante L, Grimson R (1995) Fatigue therapy in multiple sclerosis: results of a double-blind, randomized, parallel trial of amantadine, pemoline, and placebo. Neurology 45: 1956-1961

Kurzrock R (2001) The role of cytokines in cancer-related fatigue. Cancer 92: $1684-1688$

Meyers CA, Weitzner MA, Valentine AD, Levin VA (1998) Methylphenidate therapy improves cognition, mood, and function of brain tumor patients. J Clin Oncol 16: $2522-2527$

Mock V, Atkinson A, Barsevick A, Cella D, Cimprich B, Cleeland C, Donnelly J, Eisenberger MA, Escalante C, Hinds P, Jacobsen PB, Kaldor P, Knight SJ, Peterman A, Piper BF, Rugo H, Sabbatini P, Stahl C, for the NCCN Cancer Related Fatigue Panel (2000) National Comprehensive Cancer Network Oncology Practice Guidelines for Cancer-Related Fatigue. Oncology 14(11A): 151-161

Mock V, McCorkle R, Ropka ME, Pickett M, Poniatowski B (2002) Fatigue and physical functioning during treast cancer treatment. Oncol Nurs Forum 29: 338

Mock V, Pickett M, Ropka ME, Lin EM, Stewart KJ, Rhodes VA, McDaniel R, Grimm PM, Krumm S, McCorkle R (2001) Fatigue and quality of life outcomes of exercise during cancer treatment. Cancer Pract 9: $119-127$

Morrow GR, Andrews PLR, Hickok J, Roscoe J, Matteson S (2002) Fatigue associated with cancer and its treatment. Support Care Cancer 10: 389398

Morrow GR, Hickok JT, Roscoe JA, Raubertas RF, Andrews P, Flynn PJ, Hynes HE, Banerjee TK, Kirshner JJ, King DK (2003) Differential effects of paroxetine on fatigue and depression: a randomized, double-blind trial from the University of Rochester Cancer Center Community Clinical Oncology Program. J Clin Oncol 21: 4635-4641

National Institutes of Health. State-of-the-Science Panel on symptom management in cancer: pain, depression and fatigue held July 15-17, 2002 Final statement October 26, 2002. Available at http://consensus.nih.gov/ta/022/022_statement.htm

Portenoy RK, Itri LM (1999) Cancer-related fatigue: guidelines for evaluation and management. Oncologist 4: 1-10

Rammohan KW, Rosenberg JH, Lynn DJ, Blumenfeld AM, Pollak CP, Nagaraja HN (2002) Efficacy and safety of modafinil (Provigil) for the treatment of fatigue in multiple sclerosis: a two center Phase 2 study. $J$ Neurol Neurosurg Psychiatry 72: 179-183

Sadler IJ, Jacobsen PB, Booth-Jones M, Belanger H, Weitzner M, Fields KK (2002) Preliminary evaluation of a clinical syndrome approach to assessing cancer-related fatigue. J Pain Symptom Manage 23: $406-416$

Schwartz AL, Mori M, Gao R, Nail LM, King ME (2001) Exercise reduces daily fatigue in women with breast cancer receiving chemotherapy. Med Sci Sports Exerc 33: 718-723

Schwartz AL, Thompson JA, Masood N (2002) Interferon-induced fatigue in patients with melanoma: a pilot study of exercise and methylphenidate. Oncol Nurs Forum 29: E85-E90

Segal RJ, Reid RD, Courneya KS, Malone SC, Parliament MB, Scott CG, Venner PM, Quinney HA, Jones LW, Slovinec D'Angelo ME, Wells GA (2003) Resistance exercise in men receiving androgen deprivation therapy for prostate cancer. J Clin Oncol 21: 1653-1659

Spiegel D, Bloom JR, Yalom ID (1981) Group support for metastatic cancer patients: a randomized prospective outcome study. Arch Gen Psychiatry 38: $527-533$

Vogelzang NJ, Breitbart W, Cella D, Curt GA, Groopman JE, Horning SJ, Itri LM, Johnson DH, Scherr SL, Portenoy RK, for the Fatigue Coalition (1997) Patient, caregiver, and oncologist perceptions of cancerrelated fatigue: results of a tripart assessment survey. Semin Hematol 34: $4-12$

Wagner LI, Cella D (2001) Cancer-related fatigue: Clinical screening, assessment, and management. In Marty M, Pecorelli S (eds) ESO Scientific Updates: Fatigue, Asthenia, Exhaustion and Cancer, 5th edn.,) pp. 201-214, Oxford, England: Elsevier Science 
Fatigue and cancer: causes, prevalence and treatment approaches

LI Wagner and D Cella

Wagner LI, Cella D, Cashy J, Peterman AH, Paice JA, Marks BA, Shevrin DH, Muir JC, Straus J, Von Roenn J (2003a) Single item screening to detect clinically significant fatigue, pain, distress, and anorexia in ambulatory oncology practice. Proc Am Soc Clin Oncol 22: 527

Wagner LI, Cella D, Peterman A (2003b) Methodological considerations in the treatment of fatigue. In Portenoy R, Bruera E (eds) Issues in Palliative Care, pp. 173-185, Oxford, England: Oxford University Press
Weinshenker BG, Penman M, Bass B, Ebers GC, Rice GP (1992) A doubleblind, randomized, crossover trial of pemoline in fatigue associated with multiple sclerosis. Neurology 42: $1468-1471$

Wilwerding MB, Loprinzi CL, Mailliard JA, O’Fallon JR, Miser AW, van Haelst C, Barton DL, Foley JF, Athmann LM (1995) A randomized, crossover evaluation of methylphenidate in cancer patients receiving strong narcotics. Support Care Cancer 3: 135-138 